\title{
Gestión del agua e integración de políticas sectoriales. Balance y situación actual en el territorio del Alto Guadiana
}

\author{
Ángel Raúl Ruiz Pulpón
}

Universidad de Castilla-La Mancha. Departamento de Geografía y Ordenación del Territorio Angelraul.ruiz@uclm.es

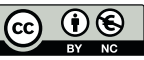

Recepción: marzo de 2011

Aceptación: junio de 2011

\section{Resumen}

La integración es uno de los principios de mayor relevancia de la Directiva Marco del Agua aprobada en el año 2000. De entre sus distintas formas, la integración de las políticas sectoriales y la coordinación entre las administraciones competentes son objetivos clave para la consecución de una eficiente ordenación de los recursos hídricos en el territorio. El estudio analiza la ausencia de este paradigma durante los últimos veinticinco años en la cuenca alta del río Guadiana, territorio con graves problemas de sobreexplotación de sus acuíferos subterráneos, y describe los últimos intentos de concertación recogidos en el recientemente aprobado Plan Especial del Alto Guadiana.

Palabras clave: integración; coordinación; sobreexplotación; políticas sectoriales; Plan Especial del Alto Guadiana.

Resum. Gestió de l'aigua i integració de polítiques sectorials. Balanç i situació actual al territori de l'Alt Guadiana

La integració és un dels principis de més rellevància de la Directiva Marc de l'Aigua aprovada l'any 2000. D'entre les diferents formes que presenta, la integració de les polítiques sectorials i la coordinació entre les administracions són objectius clau per a la consecució d'una ordenació eficient dels recursos hídrics al territori. L'estudi analitza l'absència d'aquest paradigma durant els últims vint-i-cinc anys a la conca alta del riu Guadiana, territori amb greus problemes de sobreexplotació pel que fa als seus aquífers subterranis, i descriu els últims intents de concertació recollits en el recentment aprovat Pla Especial de l'Alt Guadiana.

Paraules clau: integració; coordinació; sobreexplotació; polítiques sectorials; Pla Especial de l'Alt Guadiana.

Résumé. Gestion de l'eau et intégration de politiques sectorielles. Bilan et situation actuelle dans le territoire du Haut Guadiana

L'intégration est un des principes d'une plus grande importance de la Directive Cadre Européenne approuvée à l'année 2000. Parmi ses différentes manières, l'intégration des politiques sectorielles et la coordination entre les administrations sont plusieurs des objec- 
tives clefs pour la réalisation d'un aménagement efficace des ressources hydriques dans le territoire. L'étude analyse l'absence de ce type de paradigme pendant les dernières vingtcinq années dans le haut bassin de la rivière Guadiana, territoire avec de graves problèmes de surexploitation de ses aquiferes souterrains, et décrit les dernières tentatives de concertation rassemblées dans le récemment approuvé Plan Spécial du Haut Guadiana.

Mots clé: intégration; coordination; surexploitation; politiques sectorielles; Plan Spécial du Haut Guadiana.

Abstract. Water management and integration of sectorial policies. Results and current situation in the area of the Upper Guadiana

Integration is one of the most relevant principles in the Water Framework Directive passed in 2000. Among the various types of integration, the integration of sectorial policies and coordination between competent authorities are key objectives in efficiently regulating water resources within a territory. This study analyses the lack of this paradigm over the last twenty-five years in the upper Guadiana River basin, an area with severe problems of overuse of its underground aquifers, and describes the latest coordination attempts contained in the recently passed Special Plan for the Upper Guadiana.

Key words: integration; coordination; overuse; sectorial policies; Special Plan for the Upper Guadiana.

\begin{tabular}{cc}
\multicolumn{2}{c}{ Sumario } \\
Introducción y objetivos & Consideraciones finales \\
Integración de políticas sectoriales & Referencias bibliográficas \\
en el territorio del Alto Guadiana & \\
Últimos intentos de solución: el Plan & \\
Especial del Alto Guadiana (2008) &
\end{tabular}

\section{Introducción y objetivos}

La gestión eficaz y razonada del agua resulta indispensable en cualquier proceso de ordenación territorial. La consecución de este objetivo resulta especialmente complicada cuando nos referimos a un recurso que desempeña un papel fundamental en las actividades productivas y en la conservación de los ecosistemas naturales y, en consecuencia, condicionada por el concurso de múltiples agentes y de distintas políticas sectoriales. Precisamente es ese carácter multifuncional el que se debe poner en valor a la hora de perfilar una estrategia de desarrollo basada en la cohesión territorial que abogue por la coordinación de las políticas sectoriales, tal y como se viene insistiendo en los últimos años (Mitchell, 2005: 1337; Del Moral, 2008: 2, 2009: 1; Fernández et al., 2009: 166; España y Matarán, 2011: 1). La aprobación de la Directiva Marco del Agua (DMA) en el contexto de la Unión Europea en 2000 supuso el espaldarazo hacia estos modelos de gestión sistémica, con una nueva filosofía concretada en principios tan relevantes como la participación y 
la integración. La primera se plantea con carácter proactivo y legitimador de las decisiones adoptadas en la planificación, basadas en la transparencia y la garantía de calidad en el acceso a la información de los ciudadanos (La Calle, 2004: 92; AA.VV., 2007: 13), y asumida, por parte de los círculos políticos, como una herramienta indispensable a la hora de aportar soluciones a temas ambientales complejos (Del Moral y Pedregal, 2002: 129); mientras que la segunda sería el paradigma que unifica, interpreta y da sentido a toda la política ambiental de aguas europea.

La integración puede ser entendida desde un punto de vista interno y externo (La Calle, 2008: 13-17): internamente, se configura como aglutinador de políticas que atañen exclusivamente al agua y en el que se intenta unificar el marco jurídico de todas las categorías de aguas existentes en el ámbito de una cuenca hidrográfica; mientras que, externamente, se entiende como la coordinación eficaz entre todas las disposiciones públicas vinculadas con el agua, con cooperación entre las distintas administraciones y sus diferentes escalas de actuación. Según el considerando 16 de la Directiva, los marcos que requieren de mayor integración son las políticas energéticas, las de agricultura, las de pesca, la política regional y el turismo.

La asimilación actual de ambos paradigmas está supeditada al proceso de transposición de la Directiva al ámbito normativo español, bastante limitado desde el punto de vista jurídico y aplicado (Embid, 2007: 22; Caro-Patón, 2004: 40) y distanciado de los enunciados de las políticas hidrológicas vigentes (Bayés et al., 2003: 225), lo que determina un contexto social, económico y cultural que sigue considerando el agua como un recurso exclusivamente productivo y alejado, por tanto, de otros enfoques de gestión que apuestan por la naturaleza multifuncional de la misma, propios de una nueva cultura del agua. Aparte de estos inconvenientes, su incorporación se perfila harto difícil cuando se programa como factor de resolución de conflictos en territorios con déficits hídricos estructurales, tal y como ha ocurrido en los últimos años en la cuenca alta del río Guadiana, territorio que cuenta con una importante conflictividad derivada de la sobreexplotación de sus acuíferos subterráneos. El objetivo del presente trabajo es comprobar como la falta de coordinación entre las administraciones ha agravado el problema de la gestión del agua en el Alto Guadiana, sobre todo de las políticas dictadas para revertir el problema ambiental. El conflicto de intereses se plantea entre las disposiciones ambientales propugnadas por la Administración hidráulica y las decisiones agrarias que han estado subordinadas a la regulación de los mercados por parte de la política agraria común (PAC).

La fecha de partida será 1985, momento en que se aprobó una nueva ley de aguas que incorporaba la comprensión del ciclo integral del agua y que velaba por la gestión del dominio público hidráulico. Su puesta en marcha dispuso una amplía batería de actuaciones legales que supusieron un antes y un después en la gestión de los recursos hídricos de la cuenca alta del Guadiana. Para finalizar, haremos referencia al recientemente aprobado Plan Especial del Alto Guadiana, último intento para conseguir un uso sostenible de los acuí- 
feros, para concretar sus esfuerzos de integración y valorar las dificultades que actualmente se están sucediendo.

\section{Integración de políticas sectoriales en el territorio del Alto Guadiana}

El territorio del Alto Guadiana se localiza en la parte central de la Comunidad Autónoma de Castilla-La Mancha. Se caracteriza por la presencia del río Guadiana, que forma parte de una red hidrográfica bastante irregular y con una importante interdependencia entre los cursos superficiales y subterráneos. De éstos últimos, destaca el acuífero de la Mancha occidental (acuífero 23), que, atendiendo a los principios de delimitación administrativa que propugna la DMA, está constituido por tres masas de agua subterránea (Mancha Occidental I, II y Rus-Valdelobos) (mapa 1). Con una extensión de unos 5.500 km², la explotación incontrolada y creciente de sus recursos hídricos a lo largo de los últimos cuarenta años ha ocasionado una importante conflictividad ambiental, social y económica, hasta el punto que dicho acuífero y el del Campo de Montiel (acuífero 24) constituyen las únicas unidades subterráneas declaradas definitivamente sobreexplotadas en el territorio nacional.

La sobreexplotación conllevó la consiguiente afección de la red hidrológica superficial de la cuenca alta y, sobre todo, del conjunto de humedales que forman parte, desde 1981, de la Reserva de la Biosfera La Mancha Húmeda, que abarca un total de 294.321 hectáreas (Jerez, 2010: 13). El principal humedal de la Reserva es el Parque Nacional de las Tablas de Daimiel, que constituye uno de los ecosistemas más representativos de la formación de tablazos producidos por el desbordamiento de los ríos en zonas con escasez de pendiente y propensión al endorreísmo. Con poco más de 1.900 hectáreas, es un lugar donde el proceso de degradación ambiental se ha hecho más evidente, una vez que la red fluvial interconectada con el Parque fuera seriamente alterada por las políticas de canalización y por el efecto de la apertura de pozos subterráneos para incrementar la superficie regada. La consecuencia más visible de este proceso fue la desaparición de los manantiales de los Ojos del Guadiana en 1981, auténtico nacimiento del río Guadiana que abastecía de aguas dulces a las Tablas por su parte suroriental.

Hablando de su evolución más actual, en octubre de 2009, el Parque se encontraba en una situación de extrema gravedad, con tan sólo 10 hectáreas encharcadas de aguas provenientes de pozos colindantes y haciendo frente a un incendio de turba subterránea originado por autocombustión. Sólo la satisfactoria pluviometría del año 2010 ha posibilitado que las Tablas estén actualmente inundadas y recuperadas, al igual que otros parajes del Alto Guadiana, como las Lagunas de Ruidera.

A las alteraciones de tipo cuantitativo, habría que añadir las de tipo cualitativo, ya que el proceso de modernización e intensificación económica iniciado por las industrias agroalimentarias, la agricultura, y la ganadería originó una importante contaminación de los cursos fluviales. Fueron los vertidos de las industrias alcoholeras y la utilización intensiva de productos fitosanitarios 

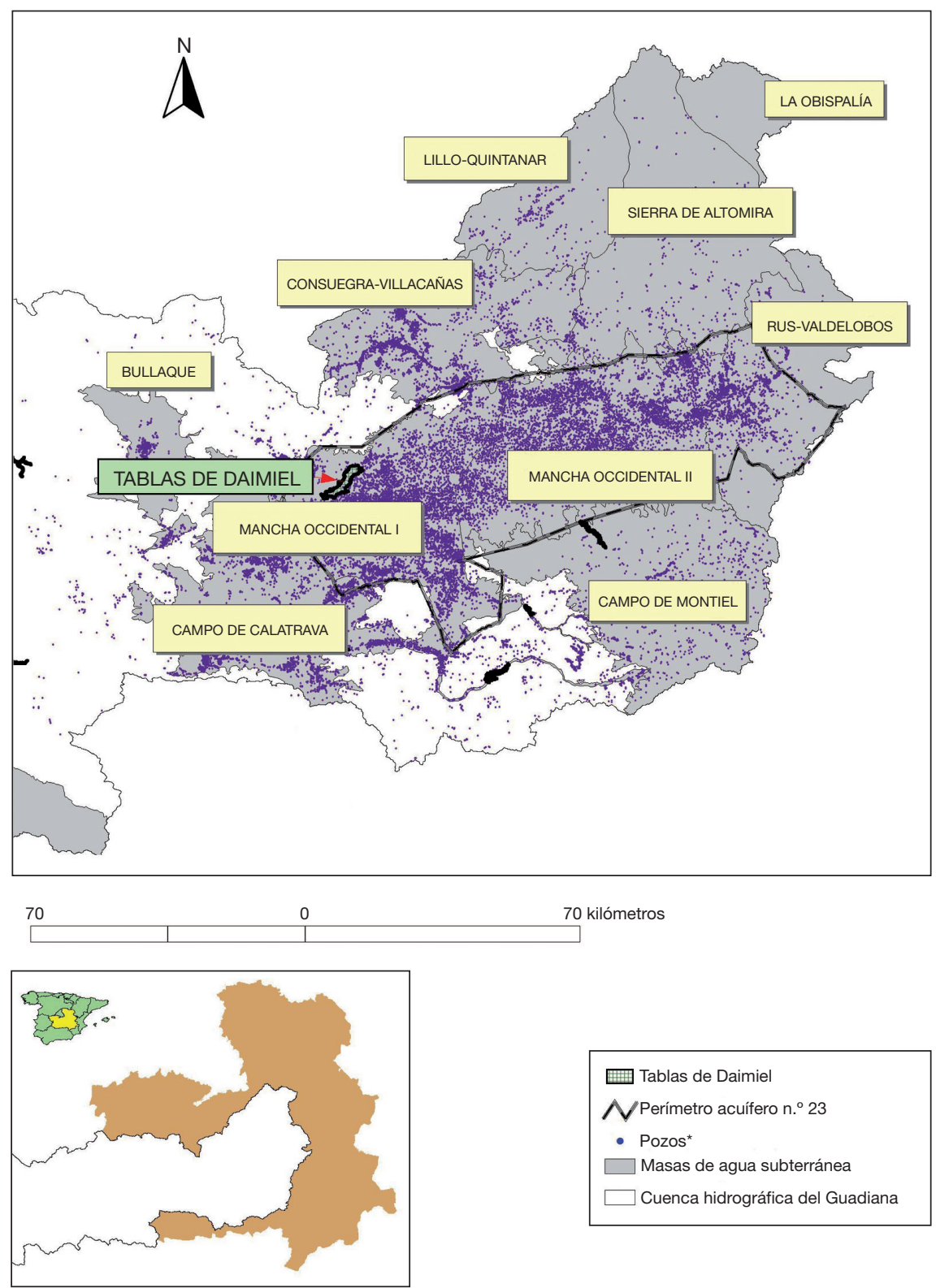

Mapa 1. Localización de las principales masas de agua subterránea en el territorio del Alto Guadiana y pozos de regadío.

Fuente: Servicio Cartográfico de la Confederación Hidrográfica del Guadiana (2010).

*Inventario de captaciones 1990 (elaboración propia). 
los que contribuyeron al proceso de contaminación de las aguas superficiales y subterráneas que se encontraban interrelacionadas con el Parque Nacional, situación que también se ha intentado revertir como veremos posteriormente.

\section{El impulso de la Administración y la sobreexplotación de los acuiferos (1968-1985)}

El impulso al regadío se definió a partir de la segunda mitad del siglo xx, momento en el que los poderes públicos, a través del Instituto Nacional de Colonización (INC) y de la Dirección General de Obras Hidráulicas, asesoraron y apoyaron la transformación. El INC se encargó, entre otras actuaciones, de la fundación de poblados de colonización y de la ejecución de las leyes de colonización, entre las que destacó el Decreto de 27 de abril de 1951, que declaraba de Alto Interés Nacional la Colonización de la zona denominada La Mancha en la provincia de Ciudad Real, estimando una transformación de 49.500 hectáreas en los términos municipales de Herencia, Manzanares y Alcázar de San Juan (Velasco, 2005: 234; Ruiz et al., 2010: 306). El drenaje de zonas húmedas fue otra de sus actuaciones. Sobresalió la aprobación de la Ley de 17 de julio de 1956 «sobre colonización y saneamiento de las tierras pantanosas que se extienden inmediatas a los márgenes del río Guadiana, Cigüela, Záncara y afluentes», que propiciaron la desecación de zonas húmedas para incrementar la superficie agraria. A tal efecto, se creó la Agrupación Sindical de Colonización, que obtuvo el apoyo de las autoridades del municipio de Ciudad Real y evaluó la extensión de terreno dedicado al saneamiento y a la desecación en unas 30.000 hectáreas (López Sanz, 1998a: 253).

Un poco después, la iniciativa privada y el apoyo de la Administración serían claves en la promoción y el desarrollo de los regadíos a finales de la década de 1960 y principios de 1970 del siglo pasado, en un contexto influenciado por la aprobación del anteproyecto del trasvase Tajo-Segura en 1968 y por la pervivencia de una legislación hídrica que predisponía a la prospección subterránea.

A pesar de que el trasvase Tajo-Segura no se puso en marcha hasta 1979, bien es cierto que su anteproyecto dictó sentencia sobre el posible disfrute de recursos superficiales provenientes del Tajo para la agricultura manchega (Pillet, 2001: 55). Ello incitó al agricultor hacia un modelo de explotación de aguas subterráneas que le permitiera garantizar unas mínimas posibilidades de desarrollo agrario. En este sentido, el propietario tenía a favor el marco legislativo, ya que la Ley de Aguas de 1879 establecía la naturaleza jurídica de las aguas subterráneas como bien de dominio privado, puesto que se consideraba que pertenecían legítimamente a quien las alumbrase (Ruiz, 2007: 176); por tanto, se permitía la privatización de un bien común de libre acceso para aprovecharlo de forma individual, circunstancia ya descrita por el «dilema de los comunes» de Hardin (Hardin, 1968: 1243-1248; Hernández-Mora, 1998: 3; Plaza, 2006: 15), y se ocasionaba una auténtica «fiebre del agua» derivada de la masiva apertura de pozos a finales de la década de 1970 y a lo largo de la de 1980 (Serna y Gaviria, 1995: 23). 
La iniciativa de los agentes privados se completó con el propio apoyo de las autoridades de la época, una vez conocido el avance de las reservas estimadas del acuífero reflejadas en el Proyecto de Estudio Hidrogeológico de las Cuencas Alta y Media del Guadiana, de 1973. La capacidad de almacenamiento, estimada en unos $12.500 \mathrm{hm}^{3}$, hizo pensar sobre las potencialidades de transformación de la agricultura manchega, tal y como se deduce de las palabras del subdirector general de Minas en su visita a Ciudad Real en enero de 1973: «la conjunción de esfuerzos y voluntades sustenta el ambicioso objetivo de posibilitar el alumbramiento del agua que calme la sed secular del campo manchego [...] convirtiéndolos en la base sólida y real del lanzamiento económico de nuestra provincia» (Velasco, 2005: 252).

Aunque éste y otros proyectos de estudio ya se hacían eco de las posibilidades de afección ambiental derivada de la íntima conexión entre las aguas superficiales y las subterráneas, lo cierto es que, en 1977, las extracciones superaban ya los recursos naturales del acuífero (Servicio General de Obras Públicas, 1991: 63). La proliferación de captaciones al amparo de una ley de aguas obsoleta y la orientación hacia cultivos con fuertes necesidades hídricas y aconsejados por la Administración (alfalfa, maíz y remolacha azucarera), motivaron el paulatino vaciado del acuífero y la consiguiente amenaza al Parque Nacional de Las Tablas de Daimiel. El déficit estimado a lo largo de los últimos veinte años rondaría los $3.000 \mathrm{Hm}^{3}$, con unos niveles piezométricos que han experimentado un descenso de 22 metros de media y que en algunas zonas ha llegado a los 35 metros (Martínez y Echavarría, 2008: 9). Afortunadamente, las abundantes lluvias comprendidas entre diciembre de 2009 y diciembre de 2010 han posibilitado una franca recuperación del acuífero cifrada en torno a unos 1.000-1.200 hm³ según el Organismo de Cuenca, lo que significaría que se haya podido recuperar alrededor de una tercera parte del déficit acumulado.

\section{Descoordinación entre las politicas agrarias y ambientales (1985-2008)}

La situación deficitaria continuó a lo largo de las décadas de 1980 y 1990, consecuencia de la descoordinación entre política ambiental y agraria. La tabla 1 representa una selección de dictámenes propuestos por la Administración que jugaron a favor y en contra de la difusión de los regadíos desde 1985, fecha de aprobación de la nueva Ley de Aguas. También recoge otras iniciativas que o bien abogaron por una mayor integración entre las políticas sectoriales, o bien incorporaron medidas concretas para atenuar la sobreexplotación.

La década de 1980 será un período caracterizado por el apoyo regional a la agricultura de regadío. El referente fundamental fue la redacción del Plan de Aprovechamientos Hidráulicos de 1986, obra de once volúmenes mecanografiados que presentaba el estado de los regadíos regionales y concretaba sus directrices futuras (Pillet, 2001: 55), con el objetivo de situar a CastillaLa Mancha en igualdad de condiciones respecto al resto de las comunidades autónomas (López Carrasco, 1987: 440). La principal preocupación era buscar 
Tabla 1. Principales medidas de carácter integrador, y de restricción y apoyo a los regadíos en el territorio del alto Guadiana (1985-2010)

\begin{tabular}{|c|c|c|c|}
\hline & Restricciones al regadío & Apoyos al regadío & $\begin{array}{l}\text { Medidas de carácter } \\
\text { integrador }\end{array}$ \\
\hline 1985 & & & - Ley 29/1985 de Aguas \\
\hline 1986 & & $\begin{array}{l}\text { - Plan de } \\
\text { aprovechamientos } \\
\text { hidráulicos de } \\
\text { Castilla-La Mancha }\end{array}$ & \\
\hline 1987 & $\begin{array}{l}\text { - Declaración provisional } \\
\text { de sobreexplotación } \\
\text { de los acuíferos }\end{array}$ & $\begin{array}{l}\text { - PAC: Política de apoyos } \\
\text { a los precios }\end{array}$ & \\
\hline \multicolumn{4}{|l|}{1988} \\
\hline 1989 & $\begin{array}{l}\text { - Inventario Regional de } \\
\text { Zonas Húmedas }\end{array}$ & & $\begin{array}{l}\text { - Programa para el fomento } \\
\text { de la iniciativa privada en } \\
\text { materia de regadíos } \\
\text { en Castilla-La Mancha }\end{array}$ \\
\hline 1993 & $\begin{array}{l}\text { - Plan de Compensación } \\
\text { de Rentas }\end{array}$ & $\begin{array}{l}\text { - PAC: Política de ayudas } \\
\text { directas }\end{array}$ & $\begin{array}{l}\text { - Plan de Compensación } \\
\text { de Rentas }\end{array}$ \\
\hline 1994 & $\begin{array}{l}\text { - Declaración definitiva } \\
\text { de sobreexplotación de } \\
\text { los acuíferos }\end{array}$ & & \\
\hline 1995 & & \multicolumn{2}{|l|}{ - Estatuto de la vid y el vino } \\
\hline 1996 & & \multicolumn{2}{|l|}{$\begin{array}{l}\text { - Programa de mejora y } \\
\text { modernización } \\
\text { de regadíos en } \\
\text { Castilla-La Mancha }\end{array}$} \\
\hline 1999 & & \multicolumn{2}{|l|}{$\begin{array}{l}\text { - OCM del vino } \\
\text { - Propuesta regional al Plan } \\
\text { Nacional de Regadíos }\end{array}$} \\
\hline 2002 & $\begin{array}{l}\text { - Plan de conservación } \\
\text { de humedales en } \\
\text { Castilla-La Mancha }\end{array}$ & & \\
\hline 2005 & & & $\begin{array}{l}\text { - Aprobación del } \\
\text { Reglamento FEADER }\end{array}$ \\
\hline 2006 & & & $\begin{array}{l}\text { - Reforma Intermedia de la } \\
\text { PAC: Aplicación del Pago } \\
\text { Único (PAC) }\end{array}$ \\
\hline 2008 & $\begin{array}{l}\text { - Plan Especial del } \\
\text { Alto Guadiana }\end{array}$ & & $\begin{array}{l}\text { - Plan Especial del Alto } \\
\text { Guadiana }\end{array}$ \\
\hline 2009 & & & $\begin{array}{l}\text { - Orden 30/11/2009 de la } \\
\text { Consejería de Agricultura } \\
\text { que regula la concesión } \\
\text { de ayudas a los planes } \\
\text { de reconversión y } \\
\text { reestructuración }\end{array}$ \\
\hline
\end{tabular}

Fuente: elaboración propia. 
alternativas al viñedo, cultivo social con serios problemas de sobreproducción, para empezar a sustituirlo por cultivos regados y el fomento de una ganadería de base forrajera. Estas directrices ya se propusieron en anteriores mandatos, como el Real Decreto 275/1984 de reconversión de viñedo, por parte del Ministerio de Agricultura Pesca y Alimentación, que significó un considerable aumento de la presión sobre los recursos hídricos de los acuíferos (López Camacho, 1987: 134; Ureña, 1997: 10).

En consecuencia, la alfalfa, el maíz y la remolacha azucarera fueron los protagonistas de los aprovechamientos regados del Alto Guadiana durante esta década, favorecidos también por la política de apoyos a los precios decretados por la PAC y por el óptimo rendimiento del maíz en Castilla-La Mancha, superior a la media nacional (Junta de Comunidades de CastillaLa Mancha, 1999: 41).

A partir de 1992, el maíz empezó a experimentar importantes altibajos en su evolución, debido a la elevada necesidad hídrica, el cumplimiento de los regímenes de explotación y a la autorregulación de extensiones de cara a no sobrepasar las superficies máximas garantizadas para percibir los subsidios (Ruiz, 2009: 7).

No obstante, del análisis de este plan de aprovechamientos hidráulicos, junto a otras disposiciones agrarias coetáneas, como el Programa para el Fomento de la Iniciativa Privada en Materia de Regadíos, de 1989, se pueden extraer algunas lecturas positivas. El plan ya aconsejaba la prohibición de realizar nuevas captaciones en acuíferos con problemas ambientales, mientras que el programa supeditaba la concesión de ayudas en zonas con problemas de sobreexplotación al permiso de la pertinente Junta de Explotación del acuífero, lo que podríamos catalogar como uno de los primeros esfuerzos por integrar política agraria e hidráulica en el Alto Guadiana.

\section{Actuaciones de la Confederación Hidrográfica del Guadiana y la reforma de la política agraria común}

El inicio de las disposiciones correctoras de la situación ambiental tuvieron un importante referente en la aprobación de la Ley 29/1985 de aguas. La consecuencia fundamental fue el reconocimiento de las aguas subterráneas como de dominio público hidráulico (artículo 2), con lo cual se dotaba al Organismo de Cuenca de nuevas vías de actuación para gestionar y conservar las masas de agua. La tarea no fue fácil, porque las posibles actuaciones de ajuste debían tener en consideración la coyuntura agraria general, condicionada por la política de apoyo a los precios agrarios tras el ingreso de España en la Comunidad Económica Europea, y también debía resolver el problema de adaptación legal de los aprovechamientos de aguas privadas reconocidos por la antigua Ley de 1879. Este proceso, llevado a cabo entre 1986 y 1989, incrementó considerablemente la conflictividad social, al no reconocer muchas captaciones existentes debido a la insuficiencia de la documentación presentada por los titulares de explotación, por el desconocimiento de gran parte de los agricultores y por 
la ausencia de entes colectivos de gestión de los recursos hídricos que hubieran facilitado la coordinación con el Organismo de Cuenca (Hernández-Mora y López-Gunn, 2003: 295; Ruiz, 2008: 671).

Entre las prerrogativas que la nueva Ley de Aguas establecía para las confederaciones hidrográficas, figuraba la posibilidad de poder declarar la sobreexplotación de unidades acuíferas subterráneas. La situación de déficit de los acuíferos de la Mancha Occidental (acuífero 23) y del Campo de Montiel (acuífero 24) condicionó su declaración provisional de sobreexplotación tan sólo un año después de la entrada en vigor de la Ley, con lo cual se inició otra vía de conflictividad social motivada por dos premisas: la suspensión de realizar nuevas perforaciones y la sanción del Plan de Ordenación de Extracciones (POE).

La prohibición configuraba una nueva relación entre el agricultor y su explotación, ya que la apertura de un pozo estaba supeditada a un permiso administrativo. La restricción perjudicaba sobremanera a aquellas explotaciones que no contaban con derechos de concesión y también suprimía la posibilidad de cualquier transformación de cara al futuro. No obstante, y a pesar de la prohibición, desde el fin del proceso de inscripción en 1989, los pozos ilegales han proliferado en el territorio, hasta el punto que no se sabe cuantos existen en realidad. Aunque la Ley fija la clausura de la prospección, lo cierto es que la presión sindical ha impedido el cierre de muchas captaciones1, sobre todo en zonas vitivinícolas, donde la ilegalidad de los riegos es más patente (Ruiz, 2010b: 339). Por otro lado, el POE implantaba un régimen de explotación anual (RE) que fijaba el volumen máximo de agua a utilizar en cada campaña y disponía el aumento de la vigilancia del dominio público hidráulico (Velasco, 2005: 121-122).

La sanción de éste último conllevó a que la Administración regional planteara alguna acción compensatoria para los agricultores que cumplían con el $\mathrm{RE}$, que habían invertido grandes sumas de dinero en infraestructuras hidráulicas (Romero y Martínez, 1997: 464) y que, en definitiva, se encontraban en una situación regulada. Para ello, se promulgó, dentro de las medidas de acompañamiento de la Reforma de la PAC, en 1992, un programa agroambiental denominado Plan de Compensación de Rentas (PCR), que ofrecía un pago compensatorio por disminuir el volumen de agua consumido y que se prorrogó hasta 2002. Los objetivos de este plan se basaron en la recuperación de los niveles de los acuíferos y en incentivar las buenas prácticas agrarias sin menoscabo en el nivel de renta de los agricultores. Los pagos sólo eran aplicables a los usuarios que estaban integrados en comunidades de regantes y que tenían sus pozos declarados.

1. Por parte del sindicato agrario UPA, se convocó una movilización ante la puerta de la Confederación Hidrográfica del Guadiana el día 1 de julio de 2005, exigiendo el fin de las sanciones y la regularización de los pozos «alegales». Desde el sindicato agrario ASAJA, se estaba en disposición, incluso, de «utilizar la violencia para que no se cerrara ningún sólo pozo" (ABC, 26/05/2005). 
Si bien fue un éxito en cuanto a beneficiarios acogidos, se cuestionó su eficacia ambiental, debido a que el agricultor comprendió el programa como una ayuda coyuntural que podía sumar a otras subvenciones otorgadas por la PAC, y no como una nueva forma de agricultura más sostenible y razonada (Viladomiu y Rosell, 1997: 24), además, no ofrecía solución alguna para los pozos ilegales, como tampoco aconsejaba sobre las acciones que habría que emprender cuando finalizara el programa (López Sanz, 1998b: 236-242; Cruces de Abia y Martínez Cortina, 2000: 58). La contradicción entre los programas agroambientales y la política de ayudas directas de la PAC muestra al territorio del Alto Guadiana como uno de sus más claros ejemplos, ya que la declaración de una tierra como de regadío suponía obtener una subvención mayor, una vez estimado un rendimiento más elevado en los planes de regionalización respectivos. Esta falta de coordinación ambiental y agraria es la que explica la evolución al alza de las superficies regadas en el Alto Guadiana desde 1988 (gráfico 1) y evidencia el fracaso de las medidas sancionadoras para detener la sobreexplotación y las dedicadas a la restauración, a la protección y a la reclasificación de los humedales del Alto Guadiana (Peinado y Plaza, 2009: 1567). En este sentido, se constata la escasa efectividad de las figuras de protección de los espacios naturales sancionadas desde 1985. Entre las aprobadas, podemos destacar el Inventario Regional de Zonas Húmedas, de 1989, y

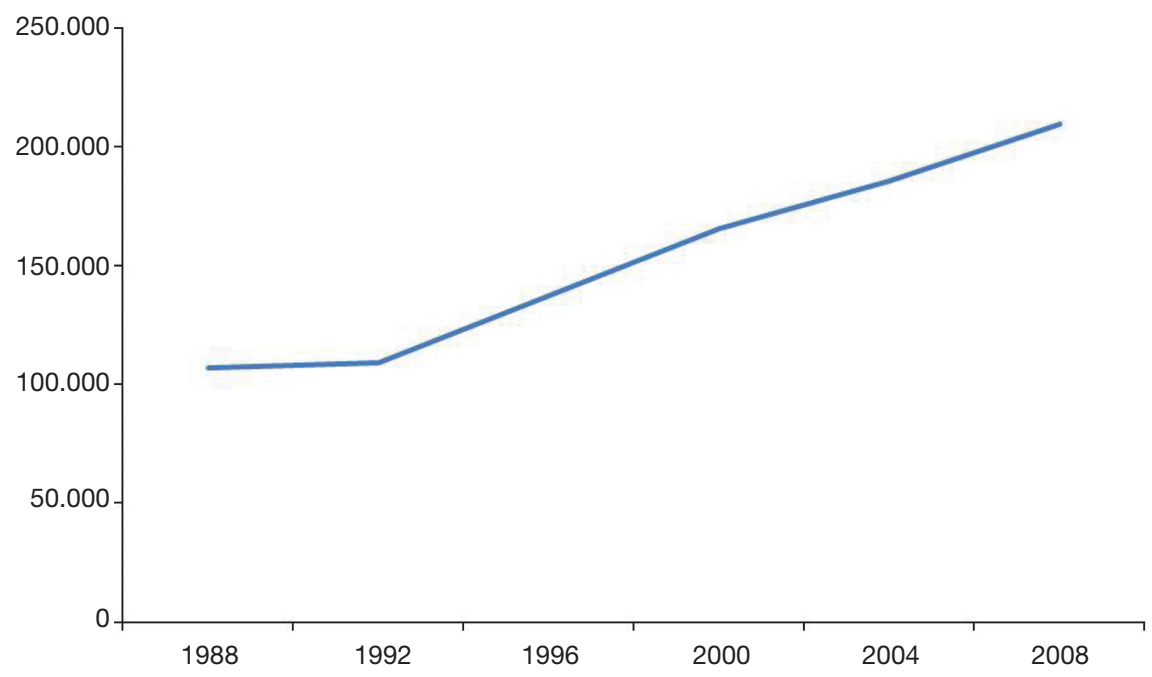

Gráfico 1. Evolución de las superficies de regadío en los últimos veinte años en el territorio del Alto Guadiana* (ha).

* Municipios que superan el 1\% del total de superficies de regadío de toda la cuenca hidrográfica.

Fuente: Consejería de Agricultura de la JCCM (elaboración propia). 
el Plan de Conservación de los Humedales de Castilla-La Mancha, de 2002, que fijaba un régimen de protección de los humedales a partir de la restricción de la actividad cinegética, de la adquisición de terrenos húmedos y de la puesta en funcionamiento de otros programas agroambientales que sustituyeran al finalizado Plan de Compensación de Rentas.

Entre 1992 y 1996, se experimentó un crecimiento de más de 28.000 hectáreas regadas protagonizado por los cereales, las oleaginosas y las proteaginosas al amparo de los pagos compensatorios, mientras que, desde 1996, el viñedo será el que marcará la pauta al ascenso debido al levantamiento de la prohibición de su riego en 1995 y la sanción de una nueva OCM del vino en 1999.

El periodo de sequía comprendido entre 1991 y 1995 abrió el debate sobre la idoneidad de seguir manteniendo la prohibición del riego establecido en el Estatuto de la Viña, del Vino y de los Alcoholes, de 1970, decidida para evitar la sobreproducción de los vinos de mesa y para garantizar la calidad de la producción (Ruiz, 2010b: 334). La Ley 8/1996, de 15 de enero, sobre medidas urgentes para reparar los efectos de la sequía levantó la prohibición en su disposición transitoria segunda, aunque era evidente que las explotaciones manchegas venían realizando un riego de apoyo desde la década de 1980 para la mejora de la productividad.

Las primeras disposiciones del gobierno de Castilla-La Mancha que amparaban estas novedades fueron el Programa de Mejora y Modernización de Regadíos en Castilla-La Mancha, de 1996, que especificaba como prioritario el apoyo a las actuaciones en materia de riego para el mantenimiento de las plantaciones tradicionales de leñosos (viñedo y olivar), y la Orden, de 14 de abril de 1997, de recuperación de viñedo afectado por la sequía, que disponía para los titulares de explotación, organizados en proyectos colectivos, unas ayudas orientadas a la recuperación del viñedo y a la mejora de la estructura productiva, comprendidas entre los 1.260 y los 1.680 euros por hectárea (Ureña, 1997: 11, Pillet, 2001). Posteriormente, la Propuesta Regional al Plan Nacional de Regadíos, de 1999, solicitaba la puesta en riego del viñedo en algunas zonas concretas de la provincia de Cuenca, con unas superficies no superiores a 500 hectáreas por término municipal, en un contexto de apoyo a los regadíos con mayor valor añadido y generadores de mano de obra (Junta de Comunidades de Castilla-La Mancha, 1999: 36).

La aprobación de una nueva OCM del vino en 1999 (Reglamento 1493/1999) supondrá una de las referencias clave para explicar el cambio experimentado en el modelo de explotación vitivinícola castellano-manchego. La readaptación de la producción al comportamiento de los mercados condicionó la apuesta decidida por la modernización y por la innovación, con un creciente número de actividades dedicadas a la crianza, al embotellado y a la exportación, y donde el papel de las administraciones fue fundamental. Uno de los instrumentos válidos para regular el potencial vitivinícola fueron los programas de mejora y de acondicionamiento agronómico, más comúnmente conocidos como "programas de reconversión y de reestructuración varietal», 
que conllevaron la transformación de los paisajes agrarios. Primero, a través del impulso hacia la irrigación, al proponer una renovación varietal, y, segundo, por la mejora de la mecanización, al introducir viñedos en espaldera. Según datos de la Dirección General Agropecuaria para 2010, este tipo de viñedo representaba más de 86.000 hectáreas en Castilla-La Mancha, con cerca de 55.000 hectáreas en el territorio del Alto Guadiana (alrededor de un 64\%), lo que supone un factor más de presión sobre los recursos hídricos del territorio, porque una espaldera se hace inviable sin un riego de apoyo, estimado en unos $2.500 \mathrm{~m}^{3}$ por hectárea y año por término medio.

Esta cuestión es relevante, porque, en las órdenes que regulaban la concesión de ayudas a la reconversión y reestructuración, no se hacía referencia, al menos hasta la Orden de 2009, a la incorporación de la irrigación como elemento indispensable, por tanto, la Administración regional no se preocupó, en ningún momento, de certificar si los solicitantes disponían o no de derecho de concesión de agua para poder tramitar la ayuda (Ruiz, 2010b: 338). Aunque este aspecto no resulta vinculante para la Administración agraria, porque no tiene competencias al respecto, se pone en evidencia una falta de coordinación entre los organismos que gestionan los recursos hídricos y la agricultura, que, como hemos mencionado, se subsanó en la Orden 30/11/2009 de la Consejería de Agricultura.

El riego de espaldera con pozos sin concesión es actualmente el principal indicador de la falta de integración en el territorio del Alto Guadiana. A un agricultor le resulta difícil de entender cómo se le sanciona su captación cuando ha obtenido, por parte de la Administración agraria, un subsidio para modernizar su explotación. Si bien es cierto que la apertura de captaciones ilegales ha agravado la sobreexplotación y es síntoma de la desidia y del desinterés social por los temas ambientales, la misma también constata la importancia de articular medidas para garantizar la viabilidad de muchas explotaciones familiares, sobre todo de tipo vitivinícola. En este sentido, y de la necesidad de convergencia entre los intereses económicos y ambientales, surgen iniciativas comprendidas en el recientemente aprobado Plan Especial del Alto Guadiana (PEAG) que permiten la regulación de captaciones que riegan cultivos sociales como la vid.

A modo de balance, consideramos que la conflictividad social en torno al uso del agua se plantea, preferentemente, por un conflicto de intereses entre la Administración y los agricultores, representados por los sindicatos agrarios y por las comunidades de regantes, más que como resultado de la movilización o de la concienciación de la ciudadanía ante la problemática ambiental. Teniendo en cuenta el ímprobo esfuerzo de diversos colectivos ecologistas y de voces del mundo científico en los procesos de participación institucional y en la divulgación de los valores ambientales de los humedales, comprobamos como la indiferencia social sigue siendo uno de los caballos de batalla más importantes en la resolución del problema de la gestión del agua en el territorio del Alto Guadiana. 


\section{Últimos intentos de solución: el Plan Especial del Alto Guadiana (2008)}

La última disposición que trata de corregir la situación ambiental, a la espera de las asignaciones que establezca el próximo Plan Hidrológico de Cuenca, es el Plan Especial del Alto Guadiana, aprobado por el Real Decreto 13/2008, de 11 de enero, donde se recoge el objeto, el ámbito territorial, la aplicación temporal y las funciones de los órganos que van a coordinar, impulsar y gestionar dicho plan. Con un presupuesto estimado de unos 3.000 millones de euros, su principal objetivo es la consecución de un uso sostenible de los acuíferos subterráneos a partir de un programa de actuaciones generales y otras de acompañamiento que permitan limitar las extracciones de agua para regadío a unos $200 \mathrm{hm}^{3}$ al año ${ }^{2}$, lo que repercutiría en la mejora de los niveles piezométricos del acuífero.

Las actuaciones generales versan sobre la reordenación de los derechos de usos del agua y la modificación del régimen de explotación de los pozos existentes, con la finalidad de convertir los derechos privados en concesionales y, de esta manera, permitir que puedan ser cedidos entre particulares, se consiga modificar el régimen de explotación de los mismos (referente a la limpieza o a los cambios de ubicación) y también a que se acceda a su compra por parte de un centro de intercambios de derechos (CID) que los rescatará para destinarlos a la recuperación del acuífero. Del volumen rescatado, el 70\% se destinaría a la recuperación ambiental, mientras que el 30\% restante se cedería a la Comunidad Autónoma, que, mediante un consorcio de gestión, reconocerá nuevas concesiones a aquellas explotaciones que se dediquen a cultivos sociales, lo que supondría una significativa experiencia de colaboración entre la administración hidráulica y la agraria según lo dispuesto en el artículo 71 del texto refundido de la Ley de Aguas de 1999 y en la disposición adicional tercera del Real Decreto-Ley 9/2006.

Las medidas de acompañamiento se enuncian a partir de varios programas y subprogramas que articulan toda una estrategia dirigida a la optimización de los recursos hídricos. Destacan los sancionados para recuperar el dominio público hidráulico, los dedicados al apoyo de las comunidades de usuarios, los programas de formación y sensibilización, así como los vinculados con la reconversión socioeconómica y la mejora de la agricultura del territorio.

\section{La integración en el Plan Especial del Alto Guadiana}

El actual Plan Especial del Alto Guadiana ha nacido con el consenso de la mayor parte de los agentes sociales. El análisis de las medidas propuestas nos lleva a acreditar el esfuerzo realizado para contentar, en mayor o menor medida, a cada una de las partes implicadas. Este trabajo de acercamiento de posturas se interpreta como una potencialidad del plan, pero, a su vez, como una amenaza debido a las altas expectativas generadas por parte de todos. El cues-

2. El Plan Hidrológico de Cuenca estima que la recarga natural de acuífero sea de unos $320 \mathrm{hm}^{3}$ anuales. 
tionamiento de las medidas implantadas se ha efectuado hasta el momento de forma tímida, con voces que denuncian la escasa dotación presupuestaria con la que ha nacido el Plan, consecuencia lógica de la crisis económica. De igual manera, el período de lluvias actual ha apaciguado la problemática al menos de una forma coyuntural, que presumiblemente despertará con toda su virulencia cuando la irregularidad pluviométrica sea mayor.

La incorporación de medidas de actuación en las distintas políticas sectoriales que emplean el agua nos permite refrendar el carácter integrador del plan (gráfico 2). Aunque su finalidad sea claramente ambiental, porque propone la recuperación del dominio público hidráulico a partir de un ambicioso programa ambiental y pretende la búsqueda de vías de actuación relacionadas con una gestión más eficiente de los recursos hídricos, es necesario también destacar el esfuerzo dedicado a implementar un nuevo modelo de desarrollo socioeconómico y la búsqueda de solución a otros problemas estructurales de gestión, como la regulación del marco concesional y el problema del abastecimiento urbano.

La optimización general del agua se establece en el Programa de Modernización y Desarrollo Agrario, para el caso de las actividades agrarias, y en el Programa de Desarrollo Socioeconómico, para el caso de las industriales. Tanto uno como otro se incluirían en el futuro Plan de Desarrollo Rural Sostenible en relación con los objetivos fijados en el PEAG. El primero contribuiría al

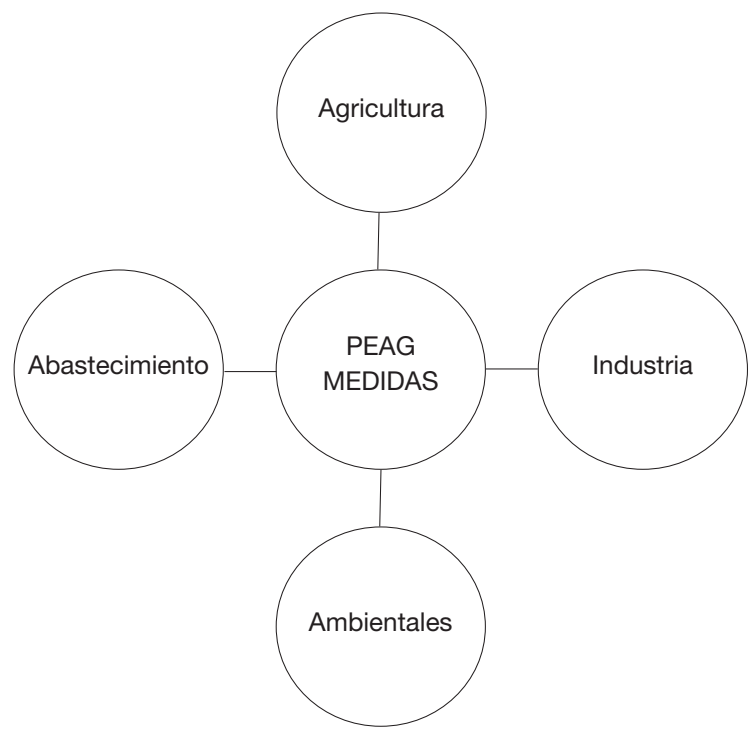

Gráfico 2. Políticas sectoriales tratadas en el Plan Especial del Alto Guadiana.

Fuente: elaboración propia. 
fortalecimiento del sector agrario a partir de varias líneas de ayudas como a la modernización de los regadíos y a las explotaciones; el apoyo a los cultivos hortícolas y al viñedo; el fomento de programas agroambientales que potencien la agricultura de secano y ecológica, y el impulso a las industrias agroalimentarias de carácter estratégico. También se expresa el deseo de introducción de los cultivos agroenergéticos y del fomento de sistemas extensivos de secano para aquellos agricultores acogidos a la venta de sus derechos, mediante la correspondiente medida agroambiental.

En cambio, el Programa de Desarrollo Socioeconómico apuesta por un modelo de crecimiento industrial basado en el uso eficiente del agua y apoya aquellas iniciativas que contribuyan al proceso de diversificación económica, como tecnología y producción de energías renovables, logística y distribución de mercancías; industria agroalimentaria; atención a las personas, y turismo.

Las directrices futuras de estas actividades están supeditadas al peculiar marco concesional y a los abastecimientos urbanos. Los titulares que poseen derechos privados tienen la libertad de acogerse al plan, tanto transformando sus derechos en concesionales para que se pueda optar a la limpieza, al cambio de ubicación y a la variación del régimen de aprovechamiento de los pozos, como a la de acceder a la venta de derechos. Es, por tanto, una pieza clave para calibrar el éxito de los programas agroambientales planteados en zonas de rescate.

Para los agricultores sin derechos reconocidos y que generan una importante conflictividad social, el Plan ha iniciado un proceso de legalización de captaciones buscando una mayor justicia en el reparto del agua, al reconocer el valor de las explotaciones de tipo familiar frente a otro tipo de propietarios, con derechos reconocidos, que utilizan el agua con fines especulativos o que siembran cultivos de limitada fuerza laboral. La idoneidad de esta medida puede ser debatida desde un punto de vista ambiental, porque se están legalizando nuevos derechos de uso en un acuífero sobreexplotado, y también desde un punto de vista agronómico, ya que las dotaciones de $700 \mathrm{~m}^{3}$ por hectárea y año que se están concediendo pueden mantener un viñedo, pero difícilmente pueden ayudar a mantener la rentabilidad del sector vitivinícola, muy castigado por el bajo nivel de sus precios. No obstante, habría que sopesar un cierto carácter integral de la medida, nacida de las peculiaridades del cultivo y de los propios criterios fijados por el Consorcio para su concesión, ya que en el viñedo se concentran ventajas ecológicas (consumo de agua inferior al de otros herbáceos, freno contra la desertización y, además, el agricultor se compromete a no incrementar el volumen de agua que se le concede); económicas (se obtienen beneficios y se palían los efectos de la sequía), y sociales (agricultura familiar, reparto más justo del agua, tradición de los paisajes del viñedo, etc.) (Ruiz, 2010b: 338).

Los abastecimientos urbanos también condicionan el desarrollo socioeconómico, a pesar de ser uno de los usos menos consumidores de agua. El PEAG asegura el abastecimiento y la depuración de aguas a las poblaciones del territorio contando con las infraestructuras ya existentes y la puesta en marcha del trasvase Tajo-La Mancha, lo que supondría una garantía de suministro 
externo que ayudaría a recuperar los niveles hídricos. El apoyo a este tipo de infraestructuras por parte del plan no hace sino refrendar la precaria calidad del agua en algunas zonas del acuífero.

\section{Consideraciones finales}

El fenómeno de la sobreexplotación y el ascenso continuo de la superficie regada son factores indicativos de desgobierno territorial. La pervivencia de los enfoques productivistas en la agricultura ha limitado los intentos de solución del problema ambiental y ha interferido seriamente en el proceso de integración de las políticas sectoriales. La mejoría de los niveles del acuífero en 2010 nos certifica que aún tenemos margen de acción para poder recuperarlo. Para ello, se hace necesario diseñar políticas más razonadas de los recursos hídricos basadas en el principio de integración y en los criterios de la ordenación territorial. Sólo el necesario diagnóstico territorial nos permitiría reconocer los problemas más relevantes de gestión y nos situaría en una inmejorable situación para identificar otros desajustes suscitados en áreas concretas del Alto Guadiana, donde, a partir de sus respectivas singularidades, poder aplicar medidas territorializadas ad hoc, abandonando así las decisiones estandarizadas sin valor operativo (Fernández et al., 2009: 170). Como ejemplo, podemos destacar la implantación horizontal de la PAC en los distintos territorios europeos o las medidas administrativas para recuperar los acuíferos, que, entre otras cuestiones, no han tenido en cuenta los distintos modelos agrarios existentes en el Alto Guadiana.

No obstante, desde la misma PAC (reforma intermedia de 2003), podemos revelar marcos de referencia teóricos e instrumentos de aplicación que podrían facilitar el proceso de integración de las políticas agrarias y ambientales (Del Moral, 2006: 49). Nos referimos, entre otros, a la obligatoriedad de desarrollar una agricultura respetuosa con el medio ambiente para poder percibir el pago único por explotación (eco-condicionalidad) y la puesta en marcha del Reglamento FEADER en 2005, que, en el segundo de sus cuatro ejes («Mejora del medio ambiente y del entorno rural»), apuesta por la gestión sostenible de las explotaciones agrarias para optimizar el desarrollo territorial.

Estas posibilidades de integración y de coordinación han quedado reflejadas en el reciente Plan Especial del Alto Guadiana. Sin embargo, y a pesar de esta fortaleza, el Plan no puede hacer frente a otras dificultades estructurales que hacen dudar de su éxito final. La segunda prórroga propuesta para el cumplimiento de los objetivos (2021-2027) queda muy lejos de los plazos impuestos por la Directiva Marco, que limita al año 2015 el acatamiento de los objetivos medioambientales para el conjunto de masas de agua europeas. Resulta perentorio, por tanto, la participación, el acuerdo y el compromiso de todos los agentes sociales, y también de las administraciones públicas, para que el Plan pueda consolidarse a lo largo del tiempo y completarse, a su vez, con el cumplimiento práctico de la Ley y la concienciación ciudadana. La inevitable irregularidad pluviométrica, el contexto económico, la falta de concienciación, 
la alternancia política y sus distintas directrices de gestión, así como el marco concesional, se constituyen como sus principales inconvenientes.

La regulación de los derechos de concesión es el tema más difícil de afrontar, ya que a la existencia masiva de pozos ilegales, se le suma el colapso administrativo que suponen más de 35.900 expedientes aún sin resolver, según refleja la memoria técnica del Plan Especial. También hay que añadir que los derechos reconocidos doblan la capacidad de recarga del acuífero de la Mancha Occidental desde la década de 1990. Ante ésta última cuestión, la única capacidad operativa con la que cuenta la Administración es la compra de los derechos por parte del Organismo de Cuenca, con un coste muy considerable si lo que se pretende es conseguir la igualdad entre las extracciones y la capacidad de recarga. El contexto de crisis económica actual pone en entredicho seriamente este tipo de posibilidades, además de hacer peligrar la ejecución de todas las medidas.

\section{Referencias bibliográficas}

AAVV (2007). Resultados del observatorio de implementación de la Directiva Marco en España. Madrid: Fundación Nueva Cultura del Agua.

Bayés, Carles; Pavón, David y Ribas, Anna (2003). «III Congreso Ibérico sobre Gestión y Planificación del Agua: La Directiva Marco del Agua: realidades y futuros. Sevilla, del 13 al 17 de noviembre de 2002». Documents d'Anàlisi Geogràfica, 42, 221-227.

Caro-Patón, Isabel (2004). «La Directiva Marco del Agua y su transposición al derecho español: análisis jurídico». Revista de Derecho Ambiental, 9, 37-57.

Cruces de Abia, Joaquín y Martínez, Luis (2000). La Mancha húmeda. Explotación intensiva de las aguas subterráneas en la cuenca alta del río Guadiana. Madrid: Fundación Marcelino Botín. Papeles del proyecto de aguas subterráneas.

EmBiD, Antonio (2007). «La Directiva Marco del Agua y algunos de los problemas de su proceso de implantación en España y otros países europeos». Ingeniería y Territorio, 80, 20-27.

EspaNAa, Mercedes R. y Matarán, Alberto (2011). «Integración agua-territorio: implicaciones de la DMA y su normativa derivada». En: Actas del VII Congreso Ibérico sobre gestión y planificación del agua. Talavera de la Reina: Fundación Nueva Cultura del Agua.

Fernández, Alfonso; Pedregal, Belén; Rodríguez, Juan Carlos; Pita, Ma Fernanda y Zoido, Florencio (2009). «El concepto de cohesión territorial. Escalas de aplicación, sistemas de medición y políticas derivadas». Boletín de la Asociación de Geógrafos Españoles, 50, 157-172.

Hardin, Garrett (1968). "The Tragedy of Commons». Science, 162, 1243-1248.

Hernández-Mora, Nuria (1998). «El papel de los usuarios en la gestión del agua en el acuífero de la Mancha occidental: oportunidades ante una situación de conflicto y carestía». En: I Congreso Ibérico sobre Planificación y Gestión de Aguas. Zaragoza: Fundación Nueva Cultura del Agua.

Hernández-Mora, Nuria y López-Gunn, Elena (2003). «La gestión colectiva de las aguas subterráneas en La Mancha». En: Coleto, Carmen; Martínez Cortina, Luis y LLamas, M. Ramón (eds.): Conflictos entre el desarrollo de las aguas subterráneas y la conservación de los humedales: la cuenca alta del Guadiana. Madrid: Fundación Marcelino Botín. Ed. Mundi-Prensa, 291- 324. 
Jerez, Óscar (2010). La reserva de la biosfera de la Mancha Húmeda y la cuenca alta del Guadiana: Guía didáctica del medio físico y de la evolución de los paisajes. Ciudad Real: Universidad de Castilla-La Mancha.

Junta de Comunidades de Castilla-La Mancha (1999). Propuesta Regional al Plan Nacional de Regadios. Toledo: Junta de Comunidades de Castilla-La Mancha.

La Calle, Abel (2004). "La participación social en la Directiva Marco del Agua». En: Martínez Gil, Javier (coord.). Una nueva cultura del agua para el Guadiana. Desde Ruidera a Ayamonte. Zaragoza: Fundación Nueva Cultura del Agua, 91-110.

- (2008). "La adaptación española de la Directiva Marco del Agua». En: Panel científico-técnico de seguimiento de la política de aguas. Sevilla: Convenio Universidad de Sevilla-Ministerio de Medio Ambiente.

López Carrasco, Fernando (1987). «La entrada en la CEE nos permitirá discutir la orientación de la política agraria comunitaria». En: Papeles de Economía Española. Economía de las Comunidades Autónomas: Castilla-La Mancha. Madrid: Federación de Cajas de Ahorros de Castilla-La Mancha, 438-440.

López SANZ, Gregorio (1998a). La gestión del agua subterránea en la cuenca alta del río Guadiana: de la confrontación a la cooperación. Ciudad Real: Diputación Provincial de Ciudad Real.

- (1998b). «De la competición a la cooperación: el marco social, político y económico». En: Cruces de Abia, Joaquín et al. (coords). De la noria a la bomba: Conflictos sociales y ambientales en la cuenca alta del rio Guadiana. Bilbao: Bakeaz, 203-273.

López-Camacho, Bernardo (1987). «El aprovechamiento de los recursos hidráulicos. Problemas actuales y perspectivas». En: Papeles de Economía Española. Economía de las Comunidades Autónomas: Castilla-La Mancha. Madrid: Federación de Cajas de Ahorros de Castilla-La Mancha, 144-158.

Martínez, Javier y Echavarría, Pilar (2008). «Detección de cambios en la ocupación del suelo y sus impactos ambientales sobre los ecosistemas acuáticos: el caso de La Mancha Occidental (España central)». En: España y el Mediterráneo: una reflexión desde la geografía española. Madrid: Comité Español de la Unión Geográfica Internacional, 41-45.

Mitchell, Bruce (2005). «Integrated water resoruce management, institutional arragements, and land-use planning». Environment and Planning, 37, 1335-1352.

Moral, Leandro del y Pedregal, Belén (2002). «Nuevos planteamientos científicos y participación ciudadana en la resolución de conflictos ambientales». Documents d’Anàlisi Geogràfica, 41, 121-134.

Moral, Leandro del (2006). "La Directiva Marco del Agua y la nueva política agraria». En: Agricultura familiar en España. Madrid: Fundación de Estudios Rurales, 44-51.

- (2008). «Integración de políticas sectoriales: agua y territorio». En: Panel científicotécnico de seguimiento de la politica de aguas. Sevilla: Convenio Universidad de Sevilla-Ministerio de Medio Ambiente.

- (2009). «Nuevas tendencias en gestión del agua, ordenación del territorio e integración de políticas sectoriales». Scripta Nova, XIII (285). [http://www.ub.edu/ geocrit/sn/sn-285.htm]

Peinado, Marta y Plaza, Julio (2009). «La Reserva de la Biosfera de La Mancha Húmeda: ¿un instrumento con capacidad operativa?». En: Pillet, Félix; CañizaREs, María del Carmen y Ruiz, Ángel Raúl (coords.). Territorio, Paisaje y Sostenibilidad. Actas del XXI Congreso de la AGE. Ciudad Real: Universidad de Castilla-La Mancha, 1561-1573. 
Pillet, Félix (2001). La Mancha: transformaciones de un espacio rural. Madrid: Celeste. Plaza, Julio (2006). Paisajes agrarios, usos del agua y sostenibilidad en Alcázar de San Juan. Proyecto de Investigación del Diploma de Estudios Avanzados. Ciudad Real: Departamento de Geografía y Ordenación del Territorio de la Universidad de Castilla-La Mancha.

Romero, Raúl y Martínez, Javier (1997): «Transformaciones de uso y estructuras agrarias en la Mancha Occidental». Estudios Geográficos, 228, 451-475.

Ruiz, Ángel Raúl (2007). Tipología territorial de la agricultura de regadío en los municipios de la cuenca hidrográfica del Guadiana. Toledo: Consejo Económico y Social de Castilla-La Mancha.

- (2007b). «Respuestas administrativas frente a la degradación del patrimonio natural de la cuenca alta del Guadiana: Estado de la cuestión». En: La Geografía en la frontera de los conocimientos. Actas del XX Congreso Nacional de la AGE. Sevilla: Asociación de Geógrafos Españoles.

- (2008). «El acceso al agua como factor de identificación de problemas de desarrollo agrario sostenible en el territorio del Alto Guadiana». Estudios Geográficos, 265, 665-686.

- (2009). «Evolución del cultivo del maíz y su relación con la sostenibilidad agraria en la cuenca alta del Guadiana (1977-2007). En: Pillet, Félix; Cañizares, María del Carmen y Ruiz, Ángel Raúl (coords.). Territorio, Paisaje y Sostenibilidad. Actas del XXI Congreso de la AGE. Ciudad Real: Universidad de Castilla-La Mancha, $1615-1626$.

- (2010). «Evolución y consolidación del viñedo de regadío en La Mancha». Boletín de la Asociación de Geógrafos Españoles, 52, 5-26.

- (2010b). «Conflictividad social en torno al viñedo de regadío en la cuenca alta del río Guadiana: necesidad de regulación». En: Leco, Felipe et al. (coords.). Territorio, paisaje y patrimonio rural. Actas del XV Coloquio de Geografía Rural de España. Cáceres: Universidad de Extremadura, 331-341.

Ruiz, Ángel Raúl; Jerez, Óscar y Serrano de la Cruz, Manuel Antonio (2010). «Repercusiones de las políticas públicas en la transformación de espacios de alto valor ambiental: contradicciones en la Mancha Húmeda». En: Cebrián, Francisco; Pillet, Félix y Carpio, José (eds.). Las escalas de la Geografía: del mundo al lugar. Libro Homenaje a Miguel Panadero. Cuenca: Ediciones de la Universidad de Castilla-La Mancha, 303-328.

Serna, Juan y Gaviria, Mario (1995). La quimera del agua: Presente y futuro de Daimiel y la Mancha Occidental. Madrid: Siglo XXI.

Servicio General de Obras Públicas (1991). «Teledetección: su utilización en la cuantificación y seguimiento de recursos hidráulicos aplicados al regadío. Proceso digital e imágenes Landsat TM de La Mancha Occidental». Informaciones y Estudios del SGOP, 51.

Ureña, Félix (1997). «Análisis de la evolución del regadío en la provincia de Ciudad Real en el período 1960-1995». En: III Congreso Nacional de Medio Ambiente. Madrid: Ministerio de Medio Ambiente, 656-668.

Velasco, Mariano (2005). Cien años en el desarrollo de la cuenca alta del Guadiana (1898-1998). Toledo: Consejo Económico y Social de Castilla-La Mancha.

Viladomiu, Lourdes y Rosell, Jordi (1997). Informe preliminar sobre el Plan de Compensación de Rentas en los regadios de la Mancha Occidental y Campo de Montiel (Programa de humedales de las Tablas de Daimiel). Barcelona: Universitat de Barcelona. 